Preface

IN OTHER LOS ANGELESES EXPLORES A tRIAD OF INTERACTING PHENOMENA: performance art in L.A. perceived, dismembered, and redreamed by me. Performance art, with its multifarious formal and conceptual permutations, constitutes the flesh and bones of this book. L.A., the history and geography within which the book resides, extends like its skin, offering both sustenance and boundary. I am a conglomerate of sensory and cognitive organs, nerves and spleens, voices and attitudes, which change with the strategic requirement of the moment. I serve the book, as much as the book serves me. I live in the book, even as I enliven it. The constant negotiations and dialogues among this triad of live matter create the rhythms of metabolism and motility for the book.

This preface may be read as a biogram that dissects the triple centers of In Other Los Angeleses. It offers insights and access to the multiple perceptual/ conceptual centers into which the book inquires. I start with what seems the most elusive and basic element among the three: the "I" who writes. I then move on to a brief contemplation of multicentricity, the analytical lens through which I study performance art in L.A. Since the concept of multicentricity is largely inspired by the particular geocultural character of L.A., the second section amounts to an emblematic sketch of the book's title persona-the city caught in its pluralistic epiphany. The next section assesses performance art as an artistic practice that deliriously celebrates its own insufficiency. A live art bound by most biological rules that condition our lives, performance art both discloses and defies its impermanence by opening itself up to spectatorial and interpretive investments. My exposé unravels how, through the re- 
cent technologies of preservation, performance art projects and ensures its own prosthetic resurrection by leaving traces for future reassemblage.

Arthur Koestler, a mystic, novelist, scientist, and philosopher who dubbed himself a "trespasser in the age of specialists," coined the word "holon" in the late I970s to elucidate the dynamic relationships between what we commonly understand as a part and a whole. ${ }^{1}$ Koestler argues that, from the domain of living organisms to that of social organization, nowhere can we find an absolute "whole," taken as "something complete in itself which needs no further explanation," or an absolute "part," regarded as "something fragmentary and incomplete, which by itself would have no legitimate existence." Instead, we find intermediary structures that may be described as "sub-wholes," which exhibit some of the characteristics of wholes and some of the characteristics of parts. Koestler proposes the term "holon," "from the Greek 'holes' = whole, with the suffix 'on' which, as in proton or neutron, suggests a particle or part" to signify these prevalent sub-wholes. Koestler's coinage accentuates the two coexisting tendencies in most living entities: "an integrative tendency to function as part of the larger whole, and a self-assertive tendency to preserve its individual autonomy."

Although we use different terms, I find Koestler's holon an intriguing precedent for my notion of "center" in a multicentric universe. I posit center as an entity that both assumes its own provisional autonomy and, voluntarily or not, admits to its interdependence on the margins. In short, "center" in my usage is a holon. In proposing what I might call a "holonic" center, however, my conceptual focus differs from Koestler's. Koestler establishes a theory of "hierarchy" consisting of "autonomous, self-governing holons endowed with varying degrees of flexibility and freedom." I stress the picture of multiplicity in which diverse holons mark their copresences without delineating their relative or deterministic positions. Despite our differences, it is in the spirit of Koestler's holons that I present multiple centers in this preface, and by extension my book, which is itself a holon.

\section{Edge Writing}

I did not realize until way into the book that I am obsessed with the concept of multicentricity probably because, as Gertrude Stein's famous linkage posits, my mind is my geography. And my geography consists of successive residencies in literally marginal locales (on the edge of a given land mass bordering on the ocean). As a Chinese Hakka born on a peripheral island, Taiwan, I was raised in a peripheral city, Taipei, and now live in a peripheral city in a peripheral state, Los Angeles in California. ${ }^{2}$ These multiple sites unified in their geographic marginality are the various centers that have sustained, cultivated, 
tormented, and disciplined my being and becoming. I never feared that I might fall from these peripheries into the unnamable abyss because these places where I made my home - however temporary and disorderly-have always been center enough for my off-center existence. I have myself convinced that, no matter how marginalized and decentered I may be, I am my own center. I look around me and see centers everywhere. I am struck—struck with the awareness that every creature walking, eating, talking, excreting, driving, blooming, flying, or dying around me has the potential, during a quake, to fall into the depth of the earth from her/his/its own center. As mortal beings, we are born equal in our centricity into a multicentric universe.

While my perception of centricity reflects the persuasion of geographies, I suspect it also has much to do with my Chinese heritage. Chung Kao (中國, "China" in Mandarin pronunciation and English transliteration) is commonly translated as the "Middle Kingdom" or the postdynastic "Middle Nation." The Chinese character Chung (中), however, can denote "being middle" as well as "being center." The modest Middle Nation is then also the self-important Central Nation. Such a paradox is implied in the original Chinese character (中), which can be used in different contexts to indicate "moderation," "equilibrium," or "primacy." I am not using this paradox to justify my own hubrisafter all, I theorize about multicentricity rather than unicentricity. Nor do I claim to establish the "essential" Chinese character, although I have noticed the combination of courtesy and arrogance to be a distinct predisposition in most Taiwanese Chinese I know. Perhaps the children of the Central Kingdom pay homage to their ancestors by seeing themselves as holons of centricity. "Chinese are like a plate of scattered sands!" Under a different light, this old saying, which I heard as a child, yields a picture of multicentricity, whose worst imago may indeed be a lump of scattered sands where every grain of sand regards itself as central.

My lexical play on being middle and being central indicates two things: (I) multicentricity is a descriptive and analytical angle but not a prescriptive politics, and (2) multicentricity implies an engagement with the idea of centricity. More pertinent to my present purpose, I wish to note the subliminal influences of cultural upbringing, which exerts its power over the acculturated subject because neither its etiology nor its symptoms are clearly detectable. That which is hidden from consciousness is easily assumed by inheritance. But I believe a cultural inheritance by default, when anatomized, may be selectively reappropriated as a critical methodology.

If my concept of multicentricity can be partially attributed to my Chinese heritage, then the interdisciplinary methodology that I've developed for my performance studies may bear the same partial ancestry. In retrospect, I notice at least three stylistic peculiarities that might be traceable to my accul- 
turated Sinofication: a hybrid discursive style, an ideographic critique and incongruous cataloging.

In my work on performance art, I've found it necessary to write in a discursive style that melds various genres and voices: description and analysis; poetry and theory; documentation and speculation; biography and extended, even tangential, interpretation; the critique of objects and the self-reflexive probing into the very critique. My hybrid discourse emulates the characteristics of my subject matter, performance art, which tends to draw on multiple disciplines and to mix theory with practice, concepts with percepts and affects. ${ }^{3}$ How can a work that strives at times to read the artist's unconscious not chart homeopathically the artist's own imaginary trajectory? The rhetorical question has offered me a rationale to see my hybrid discourse as not only valid but necessary — so long as I also maintain "critical distance" as one of my methodological centers. But this hybrid style happens to agree with a discursive propensity in classical Chinese prose works, which intentionally combine three particular disciplines: literature, history, and philosophy. "Murmurs under the pillow," the phrase I like to use as an analogy for subliminal cultural influences, may be another reason why I write the way I do.

Throughout the book I frequently apply an isolated image (the frozen posture of an artist or a documentary photograph from a performance installation) as an interpretive anchor to a particular artist's corpus or a given performance project. I read the image as a text and a map: the text, in an elliptical way, hints at a mythology yet to be discovered; the map provides a diagram for the must-see locations in that mythology. This way of reading a picture is of course a well-honed method in art history, from which I learned my craft. But I wonder if it doesn't also reflect my education in an ideographic language, which inculcates in its users the habit of reading a picture as a word remade in calligraphy. A Chinese ideogram is usually composed of numerous independent parts: like semantic holons, each of these parts has particular denotations; combined, they suggest a range of meanings for the ideogram. "Snow" (雪), for example, is composed of two larger holons: the upper part (雨) means "the rain" and the lower part ( $\exists$ ) is related to "a sweeper" or the act of "sweeping." Accordingly, "snow" means, by association, a special kind of rain that can be or needs to be swept away, or a rain too heavy for the sweeper to have any use at all, because it falls on the sweeper and buries it. I may generate even more stories by going into the smaller holons within each larger one. Thus, if my critics object that I have read too much into a given image, they are probably right.

A recurrent syntactic device in the book is the catalog, listing different topics for elaboration. I argue in chapter I that the run-on catalog is a linguistic manifestation of multicentricity, which mirrors the horizontality of L.A.'s built 
environment. Syntactically, each topic in a catalog represents a conceptual center. The various topics that I list together for my inquiry, however, may sometimes have varying significance to the ongoing argument. Why? I explain this phenomenon as a conceptual reflex of the multicentric condition, which foregrounds the surface plenitude (phenomenologically) without delving into the comparative scales among different centers. At some moments I find my multicentric cataloging a potential source of humor, of the kind demonstrated by a passage from Michel Foucault's preface to The Order of Things. Foucault traces the seed of his book to a passage from Jorge Luis Borges, who quotes from "a certain Chinese encyclopedia" that classifies animals into "(a) belonging to the Emperor, (b) embalmed, (c) tame, (d) sucking pigs, (e) sirens, (f) fabulous, (g) stray dogs, (h) included in the present classification, (i) frenzied, (j) innumerable, $(\mathrm{k})$ drawn with a very fine camelhair brush, (l) et cetera, $(\mathrm{m})$ having just broken the water pitcher, (n) that from a long way off look like flies." Amazed and amused, Foucault comments on this "Chinese" taxonomy as illustrating the Westerners' "stark impossibility of thinking that." ${ }^{\text {" While }}$ Borges, the fiction writer, might actually be the author of that alleged Chinese taxonomy, I do recognize similar inclinations toward the incongruous and the absurd in my own multicentric cataloging. Is it Chinese or is it me?

\section{The One and the Many in Multicentricity}

Along with L.A., multicentricity is a protagonist in my first chapter. I shall not overtake myself by forecasting too much what will be debated later. Instead, this section contemplates a covert thesis in multicentricity: the tension between the one and the many. The dialectics between the one and the many is a perennial fixation of mine. I cannot venture a diagnosis at this time, except to say that my book implies a quest for prognoses. In plain language, the one and the many stand for the interplay between a center and multiple other centers. They are the dialectic pair in the concept of multicentricity.

Multicentricity, in my theorization, submits three postulates: (I) the inevitability of perceptual centricity (2) the coexistence of multiple (and multiscaled) centers, and (3) the fundamental inadequacy of any one center. There is no logical sequence among these three postulates, for they both follow and lead to one another. All three imply the interrelations between the one (a single center) and the many (multiple centers). The one may be seen as the individual holon within multiple other holons or as the dynamic and mutable sum total (the One) of the many.

The first postulate comments on the condition of human perception. The perceiver, as the single center in which a set of perspectives originates, is the one enclosed within a world of many. In this instance, the center is the eyes 
who see, the ears who hear, the mouth who speaks, and the body who experiences, knows, judges, discriminates, expresses, makes mistakes, and (pro)creates. The one is the self who confronts, defies, transgresses against, or rejoices in a world of many significant, hostile, or anonymous others.

The second postulate refers to our terrestrial and cosmic existence. The life on earth consists of a multitude of perceivers, whose visions, strengths, weaknesses, eccentricities, and commonalities expend the energies that keep "life" going. When we look around us, diversity and plenitude are characteristic evolutionary predilections. Life propagates itself until it's unable or undesirable to do so. In this scenario, the one is implied by the many, even as the many are composed of many ones. Whether there is the One that has created these many is beyond my present concern, for I deal not with genesis but with existing phenomena. We know that a multitude of living beings exists. If the original One is unverifiable and varies with different spiritual beliefs, the multitudinous bodies of the present many, however, do constitute an ever-changing corpus of One. In life science, many theorists call this mutable One "Gaia" or "Mother Earth." In Taoist philosophy, the variable One is named "Tao" (道, or the Way), which is in and of itself a Book of Changes. The same reasoning sequence applies to the structural relations between the earth (the one) and a multitude of other ecosystems (the many) in the cosmos (the One?). In this context, multicentricity is only a shorthand for the zillion-year-old tension between the one and the many.

The third postulate recommends an epistemic attitude to the one who perceives in a world of many. "No man is an island—he is a holon," adds Koestler to a familiar proverb. ${ }^{5}$ I will extend Koestler's effort to include women, children, animals, fish, and plants in the ranks of holons. A holon is a center in a multicentric universe. In the model of perception I posed earlier, a center is a perceiver. Being a holon, the one who perceives cannot possibly claim that she/he/it has the omni-vision to observe and to know all, even though the perceiver cannot but depend on her/his/its holonic vision to see, to learn, and to know. This particular dilemma, I believe, pertains to all mortal, hence fallible, beings. The one relies on interactions with the many in order to understand not only the many but also the selfsame one. We may shift to the analogous paradigm of self and others for further elaboration. The self must interact with others to live and work in a world constituted by a majority of others. The self does so not just for convenience and necessity but also for pleasure and self-knowledge. For me, to recognize such fundamental selfinsufficiency is to take a different route toward the philosophy of knowing, epistemology. The awareness of multicentricity urges the perceiver to vacillate between self-affirmation (for the inevitability of perceptual centricity) and self-critique (for the impossibility of absolute knowledge). 
Now what of L.A.? Many urban theorists have observed that L.A. is built by a horizontal sprawl of various virtually self-contained cities. Some describe this trait of centrifugal development as polycentered; others, including myself, as multicentered or multicentric. The former choose the prefix "poly" perhaps to criticize the excessiveness of such development; the latter favor the slightly upbeat matter-of-factness of "multi." Poly or multi, L.A. seems to embody the very tension between the one and the many. "There are many Los Angeleses" goes a local truism. To a frequent driver, the most regional twang in this truism is that, sometimes two hours later, the highway underneath still belongs to the County of Los Angeles: there are many that coalesce as One.

\section{Performance Art: Life, Death, and Transmigration}

On May 16, 1998, I was watching a rehearsal in an officelike room inside St. Vincent's, a homeless shelter in downtown L.A. The performers were members of Los Angeles Poverty Department (alias LAPD), a performance ensemble founded by the artist John Malpede in 1985 to continue his work with homeless and formerly homeless people in Skid Row areas. Most of LAPD's performances are collectively created by the ensemble, drawing on its members' autobiographical materials. The rehearsal I attended was led by David Halenda, the assistant director, since Malpede was on sabbatical leave. I could tell that the work-in-progress played on the theme of Dr. Faustus as a migrant everyman, being tempted by Mephistopheles in various urban guises. A chorus of divine beings was added to the scene. Halenda instructed the chorus members to laugh as wildly as they could. Although he didn't specify the reason, I understood the subtext to be the equivalence between mortal folly and divine comedy. Madeline Stroup, a woman probably in her seventies, laughed so heartily and devotedly that she won a round of applause from all of us present in the room.

Six weeks later, on June 26, I attended the performance of LAPD's Paul's Place, the piece developed from the one rehearsal I witnessed. Before the show started, Halenda announced that the performance would be dedicated to Madeline Stroup, who had been with LAPD for several years and who had just passed away a couple of days ago. I read through the program that comprised a list of cast members with a brief statement by each. Next to her name, which was still on the cast list, Stroup wrote, "Here we are again. I hope we're great!" Remembering her rehearsal as a divine chorus member, I wondered if she was playing the role now on a divine stage, laughing at Paul getting lost in his places on the street.

Stroup's unexpected departure gave me a slightly shocking confirmation 
of an observation Malpede had made during our interview earlier that year. As Malpede explained, most LAPD members lead a transient life, so the company often suffers from the sudden loss of performers - to death, arrest, or other forms of disappearance. ${ }^{6}$ Malpede's remark concerned a specific challenge faced by LAPD as an organization that provides a sorely needed forum of communal activities and human contacts for a neglected population. Incidentally, his comment also brings into relief a peculiar attribute of performance art, phrased beautifully by the critic Bonnie Marranca as "the ultimate mysteriousness and heartbreak of a form valued for its ceremony of presence even as it occasions absence." 7 If I may put it to the extreme: performing is a lithesome form of dying.

So what is performance art? A historiographic account might go like this: Performance art has inherited the renegade spirit of the European avant-garde movements from the early twentieth century, extending the experimental energies manifested in such postwar international activities as action painting, Happenings, Fluxus, conceptual art, body art, feminist art, multicultural art, and environmental/earth art. It has hastened the proliferation of postmodern dance and music and spawned a significant theater genre: solo performance. It participates in community-oriented projects that link art with activism and pedagogy. It also leads the investigation into the interfaces between art, the human body, and technology. As a mode of contemporary expression, performance art encompasses a wide range of conceptual, aesthetic, politicized, esoteric, sonic, kinetic, verbal, and single- or multi-media outputs.

This neatly historicized paragraph, however, cannot convey certain recurrent discoveries during my research. The LAPD story epitomizes these discoveries, which I may sum up here: (I) Performance art is a survival art. (2) Like other live arts, performance art embodies an act of simultaneous disclosure and vanishing; yet its conceptual premise invites the spectator to continue certain forms of imaginary investments after the live event. (3) Small but extraordinary deeds are being done by ordinary people in L.A., a place known for its big-budget pursuits of surfaces.

As I argue in this book, performance art is, above all else, an art of necessity. Performance art once had a reputation of being a provocateur's vehicle to engage in taboo subjects and extreme body manipulation and to stir up ethical or political controversies. After three decades' tenure on the contemporary art scene, performance art has shifted from its underground mystique to being an easy label for any live presentation ranging from the avant-garde to the amateurish. Some performance artists, such as Laurie Anderson and Guillermo Gómez-Peña, have attained international critical acclaim, awards, and almost rock-star fame. To most of the artists covered in this book, however, performance art is still an art form with little commercial value. Even 
when commercial success is attainable, these artists consider the monetary reward a (desirable) side effect rather than the goal of practicing performance art. Their recognition of performance art's potentials as an art practice suggests how this mixed medium is positioned in the cultural and economic nexus of L.A., a recognition that also reflects the medium's historical grounding.

Historically performance art originated in visual artists' rebellion against the monolithic standard of professional expertise assumed by the art world in the I970s: a standard commercially defined by the collectibility (i.e., the formalistic polish) of an artwork. The artists' contesting of the implicit mercenary trend succeeded in radically expanding the reified artistic criteria. Such fundamental revision resulted in at least three distinct developments: (I) the equation of mere concepts as art, leading to the "dematerialization" of static artworks in the rise of conceptual art and process art; (2) the incorporation of the artist's body and other time-based elements (e.g., a live audience, a durational project, a presentation based on improvisation and without documentation) as integral components of an artwork, which can be shared temporarily but not possessed; and (3) the insistence on a blurring between art and life, aesthetics and politics, or artist and artifact. ${ }^{8}$ These developments have helped complicate the economic standing of performance art as a cultural product in L.A.

Most crucially, performance art's incorporation of transitory elements disrupts the art market's collector ethos and commodity economy. Besides, performance art's broadened function as an aesthetic model with extra-aesthetic efficacy lends itself more readily to existential and social deployments than to capitalist commodification. Both factors are reinforced by performance art's status as a live art, which greatly limits the scale of its public circulation and consumption.

As a live art, performance art shares many characteristics with other timebased arts, such as theater, ballet, and opera. Compared with these more established performing arts, however, performance art offers its practitioner a higher degree of individual autonomy and flexibility. It often places more emphasis on the process of art-making than on the finished art product. To a much greater extent than other types of live art, performance art enlists, recomposes, enacts, and exhibits the artist's life. We may even dub performance art a "live/life art" to distinguish it from other live art forms. A live/life art inspires the practitioner not only to live art as a framed segment of life, but also to live (a sequence of) life heightened by aesthetic intention as art. This strong desire to commingle art and life may be another reason why the performance artist tends to use her/his body—including that body's materiality and histories — as a basis of performance. It also motivates the artist's pursuit for interactive encounters with other bodies in the shared time/space of a theatrical matrix. 
My argument provides a clue to the emergence of performance art in the L.A. of the 1980 s as a mode closely related to the practitioner's perception, construction, and representation of the self-the nominal center for an individual life. As exemplified by the work of LAPD, performance art offers an accessible means for progressive and/or disenfranchised artists- those I call "other subjects"- to produce committed performances that foster the formation of and interactions among diverse communities. These artists practice performance art because they are compelled to, as if their very existence and sense of well-being depended on it. For them, performance art is not just another art-making method with a variable set of formal parameters, but a process of probing and displaying the conundrums of survival as a sentient, cognitive, acculturated being.

While performance art is certainly not unique to L.A., its presence in a city dominated by a powerful entertainment industry has a particular local significance. As the avant-garde film critic David James analyzes:

Hollywood affects the city first as an all-pervading, all-colonizing system of spectacular representation, almost entirely inimical to minority and working-class self-consciousness. But it is also an economic system, an industry that holds out the promise of fame for some and employment for many. On both levelsas a textual system and as a means of cultural production - it affects everything in the city, including other forms of culture. Even if these are initially maverick or adversarial to it, they can only exist in dialogue with it; and even if their intention is to displace it, in however small a way, they often benefit from its resources. ${ }^{9}$

James's incisive critique articulates the complex, and often complicitous, relationships between Hollywood's near-monopoly and other agents of cultural expressions. Within this nexus, performance art functions primarily as an alternative source of aesthetic production, one that permits the emergence of an/other cultural ecology to resist, bypass, or abate the Hollywood hegemony. In its active cultivation of multicentric habitats for other visions and voices, performance art provides a space of survival for experimental live art. Moreover, its embodied context serves up an antidote to the prevalent postmodern experiences of alienation, segregation, and mediation. Take, for example, someone like Madeline Stroup. For her, "Hollywood" might simply mean the billboards of stars underneath whose shadows she sometimes paused to avoid the sun. But performance art afforded her a sense of emplacement, if not a permanent home, for her last days in L.A.

That performance art was able to render a small miracle in Stroup's life suggests how the process of making a performance may actively serve the performance maker. In this sense, performance art revolves around a paradox: it 
serves the artist/self precisely by emplacing the artist within an environment filled with others - be they other artists in a performance ensemble or the spectatorial others in a live performance situation. The mechanism of self-other interdependence, in my opinion, has contributed to the propensity for a performance art piece to seem unfinished, a formal trait exacerbated by the artist's general reluctance to impose authorial meanings on a given work. Thus, a work that centers around the self is intentionally left to be completed by others. The artist/self relinquishes certain control over the performative action in exchange for incarnated engagements with the viewer/other. While such an exchange may be an incentive for all live art practitioners, the performance artist tends to solicit the spectatorial other's investment to the extent that the other is given conceptual co-ownership of the performance. I stress, however, that the solicitation for an immediate other's engagement derives from privileging the interactive circumstances of live art; as such, it is by no means particular to performance art. What differentiates performance art from other types of live art on this score lies in degree, not in kind.

An artwork that centers around the self is left to be completed by others. The statement foregrounds metaphorically the circuit of embodied exchanges between the artist and the viewers in a live performance context. The artist presents a rehearsed or improvised action in front of and for the sake of an audience; the audience returns the imaginary gift in kind by contributing its own covert performances - to use "performance" here in its larger implication as an intentional enactment. This scenario is likely to occur in every publicized live action, whose impacts may indeed be gauged by the circulation of explicit and implicit performances from the stage to the auditorium and back. I imagine that the relations between the explicit performance and its implicit others resemble those between a progenitor and its progeny. Like an inverse birth, a hermeneutic space is virtually carved out within the performance proper, so as to incorporate - to put into its corpusthe spectatorial other's tacit and reactive performances. These covert performances include the spectator's silent attention, tangential comments, fond recollections, and sustained critiques, during or after the live event. They are born out of the interpretive exchange occasioned by the performance; they hold the prospects of extending the reach of the originary performance. ${ }^{10}$ This analogy explains why a performance artist would desire to share the imaginary ownership of a given piece with a spectatorial other. Only when there is a fluid circulation of imaginary currencies can the act of communicative transaction between the artist/actant and the spectator/reactant be marked. And only through such communicative transaction can a performance find an opportunity to be remembered.

To be remembered, a performance has to live at least twice. For the first 
time, a performance lives an ephemeral life in actuality, its mortality consumed by the performing artists and their spectators for a designated duration. A performance cannot but complete itself by disappearing from sight/site. It fulfills the promise of its being only when it parades its own dying and signals the moment of death. Two options are open for a performance to deal with the dilemma of being time-bound. It can choose to perish with time or to defy the perishing time. For the latter option, a performance commonly resorts to a tactic of dismemberment. It ensures its possible resurrection by leaving multimedia traces: texts, videotapes, recordings, performance scores, photographs, web sites, referential documentation, peripheral testimonies, transcribed or embellished eyewitness accounts-each source acting as an imaginary center for subsequent re/creation. From then on, a performance has the potential to live again, posthumously, in virtuality. It lives an afterlife in the mind/body/imagination of whoever reassembles and reconstitutes its dispersed flesh to create a prosthetic performance, a surrogate that replaces and extends its lost origin. Although a prosthetic performance cannot fully restore or supplant the originary performance, it carries the memory and multiplies the affectability of the source performance, much as an offspring does for a beloved but absent parent. Admittedly, from the perspective of the source performance, between here and here-again something is invariably lost. Yet, I argue, something else is gained-a review, an adaptation, an artist's memoir, a scholarly book, another live performance piece, all inspired by a single source. The Theater and Its Double, as Antonin Artaud entitles his seminal book: the prosthetic performance is the double of performance art.

Let's recall my earlier contemplation of the interplay between the one and the many, which underscores multicentricity. If an originary performance is analogous to the one, then a prosthetic performance may be likened to a single realization in a pool of many re/creative possibilities. The same thesis applies to the relations between the artist, who is the authorial one, and the spectatorial recreator, who is potentially one among many. The politics of performance art therefore pivots on the dynamics of power, need, fantasy, confrontation, and symbiosis at work between its modal pair: two sentient subjects, each existing for the other-the artist/self and the witnessing/interpreting other. In this light, I suggest that performance art actually supplies a constitutive instance of multicentricity, because the artist's authorship or centricity has become conceptually dispersed and shared among many. It is worth noting, however, that the act of making available such multicentric shareholdership is not utterly altruistic. By surrendering its centricity, or selfsufficiency, performance art engenders its own return as a phantasmic collage for posterior cultural circulation. This magnanimous self-surrender allows and entices a spectatorial other to become a recreator, who dreams up a memory 
spectacle, a prosthetic performance, from the salvaged remnants of the originary performance.

\section{Other Than Elsewhere}

As its subtitle Multicentric Performance Art signals, In Other Los Angeleses collects an array of prosthetic performances that commemorate my actual and/or virtual encounters with some inimitable obelisks of flesh, the limpid but selfevaporating performances. The book hypothesizes that these multicentric performances are miniature icons and signifiers of other Los Angeleses, so far little known to their outsiders. My research excavates the performance terrains of these other Los Angeleses to uncover their fossilized remembrances of things past, in an attempt to illuminate their present morphologies and to anticipate their future mutations. I take a labyrinthine path in my excavation, not to bewilder my fellow explorers or prospective recreators, but to trace the convoluted and at times overlapped vectors radiating from the site's multiple centers. The ensuing chapters chart the eccentric configurations of these multiple centers, which have made L.A.'s performance history a vibrant series of cultural ecologies.

Chapters I and 2 serve the twofold function of introduction and substantiated critique. Chapter I employs multicentricity as a new conceptual angle from which to analyze performance art's three functions (reflective, redressive, and generative) in its dynamic interactions with other cultures in L.A. Geography, history, economics, and demographic and cultural transformations of L.A. feature as prominently as do the diverse performance genres that the city has helped engender in the past four decades. Artists sampled in this chapter include Allan Kaprow, Judy Chicago, Barbara Smith, Rachel Rosenthal, Eleanor Antin, and Chris Burden.

Chapter 2 presents an insurgent performance of myself, the-I-who-writes, as an other subject reading, writing, and living in L.A. My performative inquiry unravels the city's successive self-imaging occasions, from the three Los Angeles Festivals (1987, 1990, 1993) to two major performance art-related museum exhibitions in 1998: "Out of Actions: Between Performance and the Object, 1949-1979" at the Geffen Contemporary and "Love Forever: Yayoi Kusama, 1958-1968" at the Los Angeles County Museum of Art. As a counternarrative to the city's self-portraitures, the chapter pinpoints the motif of a feminist and multicultural continuum, which runs through most chapters. This thesis, however, will be contravened by the closing chapter, which stands as an antithesis, a thematic other, to the rest of the book. I consider this deliberate dialectic strategy a demonstration of multicentricity, which necessitates selfcritique in a macrocosm of coexisting others. 
Chapters 3, 4, and 6 each center on an artist or an ensemble. Chapter 3 singles out Suzanne Lacy as an artist who has embodied the feminist and multicultural continuum in her performance art. Lacy has contributed two decades of excellent artistic and critical work to L.A.'s performance history. Through an inquiry into her exemplary career, the chapter also tackles two innovative concepts of performance art: the politics of marginality and the affective anatomy of performance art via multiple audienceships.

Chapter 4 adopts the Cuban anthropologist Fernando Ortiz's theory of "transculturation" to explore the performance career of Elia Arce, an immigrant artist originally from Costa Rica. Transculturation suggests a way of analyzing Arce's transformation from an ensemble player to a solo artist creating her own autobiographically based self performances with pronounced feminist inflections. Arce's singular intersections with L.A.'s multicentric cultural terrains attest to performance art's vitality as a means of self-empowerment, creative expression, and cultural production.

Shifting the focus from single artists' works to ensemble performances, chapter 6 examines the conceptual power of naming evinced in the performance works collectively created by Sacred Naked Nature Girls/SNNG, a triracial, multiethnic, and transgendered group of four women artists (Danielle Brazell, Laura Meyers, Akilah Oliver, and Denise Uyehara). The chapter offers an in-depth reading of SNNG's Untitled Flesh, an all-nude performance that mines multiple ramifications of female sexualities.

At the core and the close of the book are two chapters that investigate two genres: self performance and art performance. Self performance, my term for autobiographically based solo performance, is a genre long associated with Highways, especially in the five-year period (1989-1993) when L.A. was swept by the grand experiment of multiculturalism. Chapter 5 proposes the concept of hetero-locus to analyze Highways' contributions to L.A. as a geocultural center that values, molds, and exhibits heterogeneous otherness in producing multicentric self performances. The artists whose works illustrate a diverse range of the genre in this chapter include Guillermo Gómez-Peña, Tim Miller, Luis Alfaro, Joan Hotchkis, Danielle Brazell, Dan Kwong, Denise Uyehara, and Shishir Kurup.

Chapter 7 analyzes the ontology of theatricality by grappling with a performance art genre that most approximates theater art. Art performance, antithetical to other performance genres with existential efficacy or redressive intent, holds the intrinsic components of the performance medium - the timespace-action-performer-audience matrix of theatricality-as its primary sources of expressions. The performance groups covered in the chapter include Johanna Went; Toti M. O’Brien, John O'Brien, and Steve Roden; Oguri and Renzoku; and osseus labyrint, a constellation of artists directed by Han- 
nah Sim and Mark Steger. My study scans five prevalent tendencies common to these groups (including nontext basis, body technology, improvisation-genesis, homi-xenology, and audience consumption) in order to elucidate their manifold solutions to the problems of theatricality.

Here I reach the end of a beginning, the elsewhere of an end. For whom do I write? Bodies elsewhere; voices heard and gone; faces crumpling in mnemonic ethers, turned transparent; gentle, anxious, or hastened steps lingering in sightless air, scaring bats. When prose ages and retires from labor, poetry emerges as its prosthesis. When a performance is shared and spent, memory is set in motion. Do I mourn for the new that can only grow older by remembering the already old? Or do I breathe together with the new-old so as to reanimate the old-new? Thoughts abound, visions plentiful, but inscribing them demands the rationing of small patience and daily stillness in a city propelled by transportable loneliness. Memory lies on the other shore of loneliness, where phantom others whisper so tirelessly to keep my piece of stillness spinning: on I ride, my vertigo insatiable. 
This page intentionally left blank 